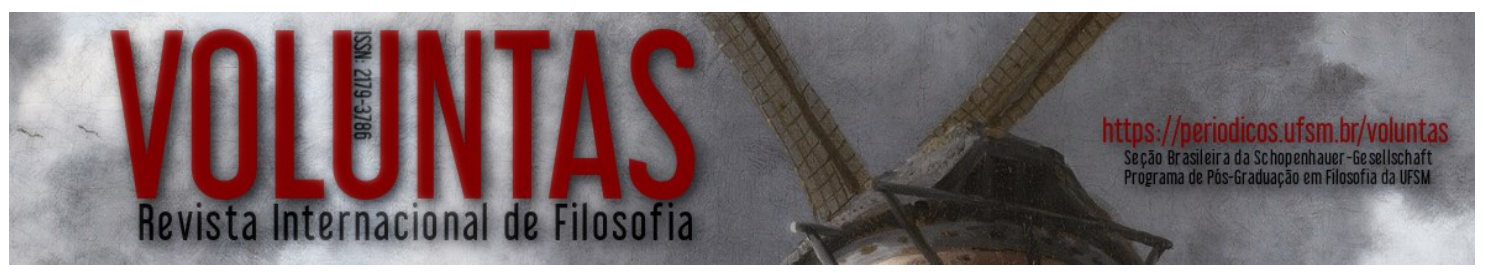

\title{
O "homem de Schopenhauer" e a filosofia: sobre a raiz schopenhaueriana da concepção de filosofia em Nietzsche
}

\author{
The "man of Schopenhauer" and the philosophy: \\ about the schopenhauerian roots of Nietrsche's conception of philosophy
}

\author{
Márcio Benchimol Barros \\ Doutor em Filosofia pela UNICAMP \\ Professor do Departamento de Filosofia da UNESP - Campus de Marília \\ E-mail: benchimolbarros@gmail.com
}

Resumo: Tendo como base uma análise comparativa entre a Terceira consideração extemporânea de Nietzsche, intitulada Schopenhauer como educador, e o capítulo dos Parerga e Paralipomena sobre a filosofia universitária, o artigo procura mostrar que o texto nietzscheano, apesar das claras divergências teóricas que manifesta em relação ao pensamento do homenageado, apresenta uma concepção de filosofia absolutamente condizente com a sustentada por esse pensamento. Argumenta-se ainda que tal concepção de filosofia não se restringe à primeira fase da produção de Nietzsche, o que é exemplificado por meio de breve consideração acerca da figura do espirito livre, tal como aparece em Humano, demasiado bumano I.

Palavras-chave: Schopenhauer; Nietzsche; Filosofia; Formação.

Abstract: On the basis of a comparative analysis between Nietzsche`s Third extemporary consideration entitled "Schopenhauer as an educator" and the chapter of Parerga and Paralipomena dedicated to the universitarian philosophy, this article aims to show that the nietzschean writing, nothithstanding all the theoretic differences it reveals in regard to Schopenhauer`s thinking, presents a conception of philosophy that is in accordance to that very thinking. It is also argued tha this conception of philosophy does not restrain itself to the first phase of Nietzsche's production, a fact that I try to indicate by briefly taking into consideration the figure of the free spirit, as it is presented in Human, all too buman I.

Keywords: Schopenhauer; Nietzsche; Philosophy; Formation.

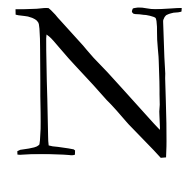

a tortuosa história da relação de Nietzsche com Schopenhauer, a Terceira consideração extemporânea, Schopenhauer como educador, ocupa uma posição de inegável importância. Primeiramente por ter sido o único texto publicado por Nietzsche dedicado exclusivamente a um único filósofo. Se David Strauss já havia sido objeto exclusivo da Primeira extemporânea, é certo que Nietzsche não o toma como filósofo, pois é apenas como erudito e devoto que é desancado. Já Schopenhauer como educador é um escrito francamente laudatório, pensado como 
homenagem e escrito em honra a um "verdadeiro filósofo". Mas o texto também ganha interesse por ocupar uma posição intermediária entre a primeira efusão elogiosa de $O$ nascimento da tragédia e a rejeição explícita de Humano, demasiado bumano I. Não é apenas sob o aspecto temporal que Schopenhauer como educador medeia entre essas duas obras: nesse escrito mesclam-se e confundem-se louvor e distanciamento de uma forma quase inextricável. Apesar da inegável sinceridade da homenagem, o texto aprofunda aquele viés crítico que já se pronunciava nas teses e conceitos decisivos de O nascimento da tragédia, dando-lhe uma expressão mais nítida, ou pelo menos mais conceitualmente palpável. Já esse personagem conceitual que é o homem de Schopenhauer - apresentado por Nietzsche na quarta parte do texto ao lado dos homens de Rousseau e de Goethe - expressa a ambivalência da atitude do homenageante em relação ao homenageado: o homem de Schopenhauer é sem dúvida pintado com as mais positivas das cores, mas a pintura também revela feições com as quais Nietzsche manifestamente não se identifica. A esse respeito teremos o que dizer mais adiante. Basta-nos, por ora, apenas a observação de que já a proposição desse personagem como correspondendo a uma espécie de tipo humano específico, colocado ao lado de outros possíveis, revela o interesse de compreender o significado do pensamento de Schopenhauer a partir de um quadro filosófico mais abrangente, que não apenas situa esse pensamento, mas, em certa medida, o explica.

Ambiguidade semelhante se pode observar na própria categoria sob a qual Schopenhauer é compreendido no escrito, a categoria do Genius: pois sob esse terminus schopenhaueriano tão importante se esconde no texto de Nietzsche um conteúdo nada schopenhaueriano. Primeiramente, nota-se que Nietzsche estende esse conteúdo significativamente para além das fronteiras do estético - dentro das quais permanece quase sempre encerrado o conceito schopenhaueriano de Genius - de modo a incluir aí também o filósofo e o santo. Não chega a ser uma verdadeira ruptura, pois o artista, o filósofo e o santo se irmanam em Schopenhauer como distintas manifestações do mesmo sujeito puro do conhecimento, e ele chega mesmo a aplicar o conceito de gênio explicitamente a Kant ${ }^{2}$, e implicitamente a Platão - já quando identifica a disposição genial como a capacidade de contemplar as Ideias platônicas. Mas a discrepância se torna visível pelo fato de que Nietzsche concebe seu gênio como um produto da cultura e da história, enquanto que o gênio schopenhaueriano, como sujeito do conhecimento puro, é, em essência, intemporal e absolutamente desindividualizado, não conhecendo, portanto, fronteiras ou condicionamentos nem culturais nem históricos. Se as filosofias de Platão e Kant se completam tão profundamente, como se abraçassem por sobre os milênios, é porque neles manifestou-se o eternamente único sujeito puro do conhecimento, e neste abraço milenar desempenha um papel

${ }^{1}$ NIETZSCHE, F. Schopenhauer als Erzieher, parte 2, in Sämtliche Werke, Kritische Studienausgabe (KSA), vol I, p. 342. ${ }^{2}$ Ver o introito da Crítica da filosofia kantiana, in: SCHOPENHAUER, A. MVR I, pp. 523-524. 
absolutamente exterior e secundário o fato de ser um deles grego e antigo, e o outro, alemão e moderno. Já para Nietzsche, tais circunstâncias desempenham um papel decisivo, vindo a determinar uma diferença essencial entre um gênio platônico e um suposto gênio kantiano.

De fato, a Terceira consideração extemporânea é explícita ao assinalar a dependência e inseparabilidade entre o gênio e a cultura na qual veio a se constituir, sendo o surgimento deste concebido como resultante do próprio desenvolvimento histórico dessa cultura. É certo que o gênio aparece ali como individualidade absolutamente singular que se destaca de todo um povo pela sua originalidade e perfeita coerência consigo mesmo. Mas ele se destaca também pela sua exemplaridade, ou seja, pela maneira como claramente reflete traços e disposições comuns desse mesmo povo. Pois ele é na verdade uma especificação totalmente individualizada e bem lograda de um tipo bumano geral tornado possível por uma cultura. Escrito no mesmo ano que Schopenhauer como educador, o texto nietzscheano postumamente publicado sobre a filosofia pré-socrática também descobre nos filósofos trágicos essa mesma superposição de traços coletivos e absolutamente individuais: cada um deles carregava em si ao mesmo tempo a marca inconfundível e indelével da cultura grega e o traço fisionômico de um caráter único que os destacava e distinguia de todos os gregos, geniais ou não ${ }^{3}$. Pois o gênio nietzscheano nasce de uma cultura, cujos traços necessariamente carrega, e esse nascimento é precedido por uma lenta gestação que se confunde com a própria história dessa cultura. Ele não é como um relâmpago iluminando subitamente um panorama de obscuridade, mas sim como um sol cujo nascimento precisa ser precedido pelos alvores de uma paciente aurora. Este alvorecer não é outra coisa que o trabalho conjunto de todas as gerações que se dedicaram à cultura, pois, a rigor, participar da cultura não é nada diferente de participar da gestação do gênio:

Este é o pensamento fundamental da cultura (der Grundgedanke der Kultur), na medida em que esta pode somente exigir de cada um de nós uma única tarefa: fomentar a geração do filósofo, do artista e do santo em nós e fora de nós, e com isso trabalhar para a plena realização da natureza4 ${ }^{4}$.

Todos os que de uma forma ou de outra se veem abrangidos pelo círculo da cultura atendem ao distante chamamento do gênio, de quem são, mesmo inconscientemente, os indispensáveis auxiliares e precursores. Cada um deles, através de seu próprio empenho nesse âmbito, participa do lento trabalho de trazer

\footnotetext{
${ }^{3}$ Cf. NIETZSCHE, F. Die Philosophie im tragischen Zeitalter der Griechen, in Kritische Studiensausgabe (KSA), volume I. A relação entre os "filósofos trágicos" e a cultura grega é trabalhada especialmente nos dois primeiros capítulos do escrito.

${ }^{4}$ NIETZSCHE, F. Schopenhauer als Erzieher, parte 5, p. 382.
} 
à luz um tipo humano cada vez mais pleno, para o qual eles mesmos são apenas esboços preparatórios:

Todo aquele que se devota à cultura declara com isso: "Vejo acima de mim algo de mais elevado e mais humano que eu mesmo; ajudai-me todos a alcançá-lo, assim como eu quero ajudar a todo aquele que reconheça o mesmo e sofra com isso, de modo que, finalmente, volte a surgir o homem que se sinta completo e infinito no conhecer e no amar, no contemplar e no poder, e que, com toda a sua completude, se vincule internamente à natureza como juiz e medida do valor das coisas"5.

Torna-se manifesto que a essa "teleologia do gênio" subjazem concepções de História e de ser humano absolutamente estranhas ao pensamento de Schopenhauer, o qual, como sabemos, só pode ver na sucessão das eras e gerações a infinda série de variações sobre um mesmo tema, a eterna reiteração da mesma e ahistórica ideia do homem, reiteração essa que apenas episódica e aleatoriamente logra trazer à luz individualidades excepcionais, justamente aquelas que são capazes de vislumbrar o caráter ilusório da passagem do tempo.

Mas, não obstante toda divergência teórica, Schopenhauer é condignamente incensado e louvado na Terceira consideração extemporânea, referido como um verdadeiro mestre e, de fato, como mestre pessoal indispensável na trajetória do autor do escrito. Isto nos coloca imediatamente diante de uma questão: se Nietzsche se afasta flagrantemente de tão importantes posições filosóficas de Schopenhauer, precisamos nos indagar qual teria sido o caráter e o sentido da poderosa influência que, de acordo com o próprio texto, o segundo exerceu sobre o primeiro. O título do escrito nos pode auxiliar nisto. A julgar por ele, Schopenhauer teria sido para Nietzsche, antes de mais nada, um educador, ou formador (Bildner), como o texto também se expressa ${ }^{6}$. A Schopenhauer deveria Nietzsche, portanto, nada menos que sua formação, e de fato, como facilmente se percebe, sua formação como filósofo. Já no segundo tópico do texto, conta-nos Nietzsche sobre sua ardente e profunda esperança juvenil de que

o terrível esforço e dever de educar a mim mesmo me seria abreviado pelo destino, pois no momento adequado encontraria um filósofo que me educasse, um verdadeiro filósofo a quem se pudesse obedecer sem pestanejar, por nele poder-se confiar mais do que em si mesmo ${ }^{7}$.

Mas esta influência benfazeja teria de dar-se segundo um conceito de formação diverso daquele clássico, oriundo da Paidéia grega, que a compreende como

\footnotetext{
${ }^{5}$ Idem, parte 6, p. 385.

${ }^{6}$ Idem, parte 1, p. 341.

${ }^{7}$ Idem, parte 2, pp. 341-342.
} 
desenvolvimento unitário, harmônico e concomitante de todas as potencialidades latentes no indivíduo. A este conceito, Nietzsche opõe um outro de caráter claramente individualizante, segundo o qual uma única potencialidade ou talento se destaca, por sua intensidade, de todos os outros, tornando-se o centro organizador e unificador do processo de formação individual. Não se trata propriamente de uma rejeição da ideia clássica de formação, mas sim da delimitação do campo em que é aplicável, ou seja: o das naturezas medianas, destituídas de qualquer talento excepcional. Aos indivíduos que possuem tais talentos, porém, deve ser permitido seguir livremente sua inclinação mais poderosa, tendo-se apenas o cuidado de não consentir que um direcionamento unilateral de suas energias acabe por privar seus outros talentos de manifestar-se. E é de fato isso mesmo que o jovem Nietzsche esperava de seu sonhado filósofo-educador.

Aquele filósofo educador que eu sonhava para mim poderia não somente descobrir a força central, mas também impedir que ela agisse destrutivamente sobre as outras forças: seria mesmo a sua tarefa educativa transformar o homem todo em um vivo e movimentado sistema solar e planetário, conhecendo a lei de sua mecânica superior ${ }^{8}$.

Ora, esta força central, esta inclinação mais poderosa revelou-se claramente ser, no caso de Nietzsche, a inclinação filosófica, e sua biografia nos permite ver em Schopenhauer justamente aquele filósofo que o fez descobri-la. Segundo seu próprio relato, seu encontro quase casual com $O$ mundo como vontade e representação teria provocado o abalo intelectual que colocou definitivamente o movimento de sua formação nos trilhos incertos e perigosos da filosofia, em detrimento de uma glória fácil e já assegurada no campo da ciência filológica ${ }^{9}$. Ora, Schopenhauer não poderia ter revelado ao jovem filólogo sua própria inclinação filosófica se não tivesse sido imediatamente reconhecido por este como verdadeiro filósofo, o que nos leva a cogitar que sua principal e mais profunda influência sobre Nietzsche talvez não esteja em haver-lhe supostamente ensinado alguma doutrina filosófica, mas sim em haver-lhe ensinado, exatamente na qualidade de um verdadeiro filósofo, o que é a própria filosofia e o filosofar. Na apreciação desta hipótese é útil nos voltarmos para um texto de Schopenhauer que muito nos fala sobre sua concepção de filosofia e encontra claro eco nas páginas da Terceira consideração extemporânea, bem como em outros escritos contemporâneos de Nietzsche: o capítulo dos Parerga e Paralipomena intitulado Sobre a filosofia universitária.

Neste texto, afirma Schopenhauer que a filosofia propõe-se a servir "[...] à tentativa da razão de, a partir de seus próprios meios e independentemente de toda

8 Ibidem, p. 343.

${ }^{9}$ A respeito, ver: JANZ, C.P. Friedrich Nietzsche - Biographie, Vol 1, Erster Teil, capítulo Die beiden ersten Leipziger Jahren. 
autoridade, resolver o problema da existência (das Problem des Daseins)"10. A afirmação é interessante porque nela vemos a filosofia definida quanto a seus meios (os meios da razão, do pensamento abstrato e conceitual); quanto a seu princípio epistêmico específico (a independência absoluta em relação a todo pressuposto não colocado por ela mesma); e, especialmente, quanto a seu objetivo: a resolução do problema da existência, compreendido como conjunto de indagações ético-metafísicas diretamente colocadas pela condição humana enquanto tal. Esta delimitação da motivação primordial da filosofia encontra-se confirmada ao longo de todo o texto, como, por exemplo, quando, mais adiante, afirma o autor ser o mais alto objetivo da filosofia " [...] a satisfação daquela nobre necessidade que chamei de metafísica, a qual, em todos os tempos, fez-se sentir interior e vivamente à humanidade"11. Já a condição para a colocação deste problema, e portanto para a filosofia, identifica Schopenhauer como a "apreensão objetiva do mundo e de nossa existência"12. A apreensão objetiva do mundo e a de nossa existência aparecem aqui unidas porque na verdade são mutuamente dependentes, pois o mundo objetivamente apreendido não é nada além da representação desse mesmo sujeito cuja existência constitui o problema original da filosofia, não possuindo nenhuma existência senão em relação a ele. O estranhamento filosófico em relação ao mundo expresso na frase inicial de $O$ mundo como vontade $e$ representação, "o mundo é minha representação", expressa simultaneamente o espanto diante do fato de estar-se diante deste mundo e a admiração diante da percepção imediata de si mesmo como sujeito dessa representação, do que decorre naturalmente a problematização filosófica da existência individual e de tudo o que a ela se relaciona. Por isso, a propensão filosófica pode, como sugere a sequência do texto, anunciar-se no espírito pela tomada de consciência acerca da verdade a priori de que o mundo é nossa representação ${ }^{13}$, mas não pode deter-se nela sem avançar em direção à consideração do "incomparavelmente mais importante de todos os problemas"14.

Precisamente como via de satisfação da necessidade metafísica, a filosofia jamais é veleidade do espírito ou caminho de vida passível de ser ou não livremente escolhido dentre outros, mas impõe-se sempre como necessidade existencial imperiosa àqueles em que viceja uma genuína propensão filosófica. Estes, porém, são raros e naturalmente raros, pois devem possuir ao mesmo tempo um intelecto que por sua extraordinária potência se liberta da condição de instrumento da Vontade - condição já em si raríssima - e uma natural inclinação ao pensamento abstrato-conceitual. Tais escolhidos da filosofia cedo ou tarde certamente a encontrarão e a saberão reconhecer nas obras dos grandes filósofos, pois “[...] tudo

\footnotetext{
${ }^{10}$ SCHOPENHAUER, A. P, Über die Universitätsphilosophie, in: Sämtliche Werke, p. 163.

${ }^{11}$ Idem, p. 168.

12 Idem, p. 215.

13 Cf. SCHOPENHAUER, A. MVR I, \1, p. 43.

${ }^{14}$ SCHOPENHAUER, A. P, Über die Universitätsphilosophie, p. 203.
} 
que se ama e que nasce um para o outro, encontra-se facilmente: almas aparentadas saúdam-se já desde longe"15. O encontro com as doutrinas filosóficas não lhes implantará a propensão filosófica, pois essa já lhes acompanha desde sempre, mas bem poderá torná-la consciente e estimulá-la vivamente. Já o homem não filosófico, o comum e corrente produto de fábrica (Fabrikwaare) da aristocrática natureza, em que o intelecto se dedica inteiramente e com gosto ao serviço da Vontade, se ocupará em vão com a obra dos grandes filósofos: também nele será impossível implantar a propensão filosófica, simplesmente porque esta contradiz sua disposição natural. Isto, porém, talvez não o impeça de ter contato com tais obras, de ocupar-se da filosofia, inclusive profissionalmente, tornando-se professor de filosofia. Mas em sua pobre compreensão, as maiores obras filosóficas não passarão de um conjunto de frases vazias, cuja sonoridade talvez seja até capaz de imitar, mas apenas para produzir uma tagarelice douta e obscura, totalmente destituída de autenticidade, já que afastada de qualquer interesse na resolução do grave problema a que se dedica a filosofia. Mas esse ainda não é o maior perigo que ronda a filosofia: seu rebaixamento à condição de palavrório oco a habilita a degradar-se ainda mais, tornando-se dócil porta-voz das opiniões tradicionais da religião local (Landesreligion) e do Estado. Pois estas são instituições que de forma alguma se interessam pela resolução do problema da existência, mas sim por outra tarefa, importantíssima, é certo, mas totalmente diversa: tornar possível a coexistência, a menos violenta possível, entre os homens, ou, como diz Schopenhauer,

garantir ordem, tranquilidade e paz entre os muitos milhões de uma raça formada, em sua grande maioria, de seres dotados de ilimitado egoísmo, injustos, grosseiros, desonestos, invejosos, maldosos, e além disso, também bastante limitados e teimosos $[\ldots]^{16}$

Não é que Schopenhauer menospreze o valor de tais objetivos ou negue a utilidade das opiniões difundidas e estimuladas por semelhantes instituições. Ocorre, porém, que a utilidade não é critério para a filosofia, cuja busca intransigente pela verdade a pode conduzir - e frequentemente a conduz - por caminhos bem diversos daqueles indicados pela utilidade. Por isso, a primeira coisa que a filosofia deve exigir de seus seguidores autênticos é independência. "O verdadeiro filosofar exige independência"17, diz Schopenhauer. Seu modus operandi, como já vimos, implica "independência de toda autoridade", não importando quão úteis se revelem as opiniões emanadas da autoridade. Pode-se dizer, então, que para Schopenhauer pertenceria essencialmente à inclinação filosófica uma vontade de independência

\footnotetext{
${ }^{15}$ Idem, p. 159.

${ }^{16}$ Idem, p. 167.

${ }^{17}$ Idem, p. 218.
} 
intelectual, um desconfiar por princípio de todo e qualquer pressuposto oculto ou não examinado, não necessariamente para negá-lo, mas pelo menos para permitir um olhar próprio e original às coisas e ao mundo, condição necessária para uma "consideração puramente objetiva do mundo e de nossa existência”.

É em suma essa concepção de filosofia que Nietzsche tenta condensar na figura do já mencionado homem de Schopenhauer. A inclinação eminentemente filosófica deste personagem deriva diretamente de sua profunda ligação ao problema da existência. "Por que eu vivo? Que lição devo aprender da vida?"18. Estas são as questões que o movem, e a obstinação com que se põe em busca das respostas para elas é o que definitivamente o afasta da convivência dos que estão à sua volta. Pois logo ele percebe com perplexidade que a preocupação que determina todo seu viver e agir é totalmente estranha à imensa maioria dos seres humanos, e que tudo no mundo parece muito mais estar ordenado a fim de que "[...] a vida, por meio de uma contínua distração dos pensamentos, não seja percebida [...]". Ele não ignora “[...] como se pode tornar a vida fácil e o quão macia é a cama na qual se poderia estender, caso se dispusesse a comportar-se, para consigo mesmo e para com os que o circundam, de acordo com os usos e costumes aceitos"19, mas não pode senão desprezar todas as facilidades e comodidades que os homens preparam para si mesmos a fim de evitarem o problema que ele reconheceu como o seu, mas que forçosamente diz respeito a todos. Cuidadosamente rejeita as armadilhas insidiosas com que os homens o desejariam "enganá-lo a respeito de si mesmo", e tem os sentidos atentos para "uma espécie de acordo (Übereinkunft)" cujo objetivo consiste em desviá-lo de seu caminho solitário, ou, como se expressa Nietzsche, “arrancá-lo de sua toca”. Diante de tais perigos, porém, ele exclama resoluto: "quero permanecer meu!"20.

Vemos, então, o quanto esse homem de Schopenhauer, tal como o constrói Nietzsche, se enquadra na caracterização que este faz do gênio como indivíduo singular e maximamente apto à autodeterminação. Mas este é um gênio decididamente schopenhaueriano, o que se pode notar especialmente pelo fundamento ético-metafísico de sua doutrina pessoal, o qual, naturalmente, coincide com aquele professado pelo filósofo de Frankfurt. Aquilo que o atrai ao homem de Schopenhaner é exatamente o que atemoriza a todos os outros, ou seja, "justamente perceber a vida, ou seja, sofrer com a vida". Nesta equiparação direta entre sentir a vida e sofrer com a vida está implícita a doutrina schopenhaueriana da igualdade entre viver e sofrer. Por isso, o homem de Schopenhauer não se pergunta apenas "por que eu vivo?" e "que lição devo aprender da vida?", mas também "como me tornei aquilo que sou e por que sofro por ser assim?" Trata-se de uma dupla pergunta, que requer uma resposta também dupla: primeiramente sofremos pelo que somos e, em segundo lugar, por aquilo em que nos

\footnotetext{
${ }_{18}$ NIETZSCHE, F. Schopenhauer als Erzieher, parte 4, p. 374.

${ }^{19}$ Idem, p. 373.

${ }^{20}$ Idem, p. 374.
} 
tornamos. Aquilo em que nos tornamos difere do que realmente somos, porque, para o homem de Schopenhauer, o tornar-se é sempre a característica do inessencial. "No vira-ser...", medita ele, "tudo é vazio, enganador, superficial e digno de nosso desprezo; o enigma que o homem deve resolver só pode ser resolvido a partir do ser"21. Resolver o problema da existência a partir do ser implica, porém, compreender essa existência como essencialmente sofrimento e carência, ou seja: implica perseguir exatamente aquele conhecimento de que o comum dos homens tão pressurosamente procura se afastar. E a maneira pela qual se afastam de seu verdadeiro ser consiste exatamente no identificar-se com tudo aquilo que em sua pessoa é somente superficial, circunstancial e fruto do devir; com tudo aquilo, justamente, em que nos tornamos, em razão de nossa inevitável participação nessa "comédia compartilhada" (gemeinsame Komödie) em que atuamos "sob cem máscaras, como jovens, homens, anciãos, pais, cidadãos, sacerdotes, funcionários, comerciantes" 22 . O erro do homem comum é o de buscar a felicidade por meio da participação nesse teatro de sombras da vida pública, quando, na verdade, ao fazê-lo está apenas a atiçar aquele querer infindo que é a fonte eterna do sofrimento. A salvo dessa perigosa ilusão, o homem de Schopenhauer consolase com as palavras de seu mestre: "Uma vida feliz é impossível: o mais alto que o homem pode conquistar é um curso de vida heroico [...]"23. E a vida heroica é aquela em que o próprio indivíduo se oferece como primeiro sacrifício e nega em si mesmo o princípio do querer:

O homem de Schopenhauer assume em si o sofrimento voluntário da veracidade, e esse sofrimento lhe serve para mortificar sua vontade própria (Eigenwille) e para preparar aquela total transformação e redirecionamento de seu ser cuja realização é o genuíno sentido da vida ${ }^{24}$.

Percebe-se bem o distanciamento que o autor da Terceira consideração extemporânea toma do homem de Schopenhauer ao descrevê-lo. Pois, já para o jovem Nietzsche, jamais o genuíno sentido da vida poderia consistir na autonegação da vontade, ou seja, da própria vida em sua mais profunda essencialidade. Já desde então seu pensamento é atraído para uma direção oposta àquela para a qual aponta o homem de Schopenhauer (bem como o próprio Schopenhauer), nomeadamente, para o fato de que a vida, apesar de todo o sofrimento que certamente lhe é inerente, é sempre e infinitamente capaz de criar um sentido para si mesma, e, através desse sentido, justificar-se. A negação do valor da vida será sempre para Nietzsche nada mais que o sintoma de uma vida enfraquecida e decadente. A vida ascendente, saudável, quer a si mesma porque é ao mesmo tempo força poderosamente criadora (artística, como ele

\footnotetext{
${ }^{21}$ Ibidem.

${ }^{22}$ Ibidem.

${ }^{23}$ SCHOPENHAUER, apud NIETZSCHE, in: op. cit., p. 373.

${ }^{24}$ Idem, p. 371.
} 
dizia em $O$ nascimento da tragédia) e o objeto em que se exerce essa potência criativa: seu impulso mais básico não é o da autopreservação ou conservação, mas sim o do ir além de si mesma, de recriar-se. A vida ascendente é aquela que está empenhada na criação de possibilidades de existência cada vez mais elevadas, mais belas e singulares, e sua autoafirmação não é outra coisa que sua identificação com este profundo e essencial impulso criador.

É exatamente essa concepção que vem à tona na já referida "teleologia do gênio" da Terceira consideração extemporânea. De fato, nela pode-se identificar um elemento polêmico profundo em relação a Schopenhauer: por meio dessa concepção, Nietzsche se contrapõe a seu mestre no que se refere à questão do valor da existência. Como produção de uma forma de existência superior, a geração do gênio não é somente objetivo último da cultura, mas também, como vimos, da própria vida ou natureza, convertendo-se, portanto, em forma de afirmação da vida e fonte de justificação da existência. Pois é essa produção que confere sentido e justifica todo o fazer e viver de todos os que dela participam. Neste processo, portanto, é a vida que se afirma como tendência à constituição de possibilidades de existência cada vez mais raras e bem-acabadas, e é por isso que a atividade do Kulturmensch - em uma cultura sadia, bem entendido - é em essência e necessariamente afirmadora da existência. Evidentemente, esta posição já está implícita em $O$ nascimento da tragédia pela própria adesão de seu autor ao projeto cultural wagneriano, por meio do qual julgava ser possível contribuir para trazer à vida o gênio trágico alemão, sem dúvida diverso do grego, mas capaz de com ele ombrear em grandeza e beleza.

Mas não obstante todo esse distanciamento, não é difícil perceber no caráter desse homem de Schopenhauer, bem como nas páginas de Sobre efilosofia universitária, alguns traços significativos de uma concepção de filosofia que Nietzsche defenderá não apenas em sua primeira fase, mas também durante toda a sua trajetória. Facilmente se recordará neste contexto o tema da aristocracia do espírito, defendida por Nietzsche - no meu entender, por motivos semelhantes aos alegados por Schopenhauer - como causa da raridade dos filósofos. Com particular evidência também se destaca aqui sua radical exigência de independência da filosofia em relação a qualquer autoridade, no que se inclui não apenas a autoridade do Estado, mas também a autoridade das tradições em geral, tenham elas caráter religioso, cultural, moral, filosófico ou qualquer outro. Conhecido é o zelo com que Nietzsche procura desencavar e pôr à luz os pressupostos escondidos nas maneiras tradicionais de pensar e agir, do que deriva aquela tendência constante à desconfiança em razão da qual veio a ser caracterizado pela filosofia francesa do século XX como um dos mestres da suspeita. O fato de que esta reivindicação de independência para a filosofia já se afirme tão pronunciadamente na Terceira consideração extemporânea, mas também em textos contemporâneos a ela, nos sugere o quanto esse traço polêmico do pensamento nietzscheano tem a dever a Schopenhauer. 
Penso, porém, que a concepção schopenhaueriana de filosofia deixa uma marca ainda mais profunda em Nietzsche, da qual os aspectos recém destacados não são senão consequências. Refiro-me à profunda e essencial relação entre filosofia e vida, à concepção de que o filosofar só se pode legitimar como parte de um processo vital, como momentum intelectual de um movimento de vida. Em seu já mencionado ensaio sobre a filosofia pré-socrática, o autor destaca com admiração justamente o fato de que o pensamento dos primeiros filósofos gregos se integrava perfeitamente à sua maneira de viver, sendo dela tanto expressão quanto princípio constitutivo. Mas a exigência de unidade entre pensar e viver é também proclamada de forma não menos enfática tanto em Schopenhauer como educador como em seu escrito sobre o futuro das instituições de formação alemães - e, como se sabe, ainda no Zaratustra essa exigência encontra vigorosa expressão.

E também no que se refere ao fundamento dessa exigência de unidade entre viver e filosofar Nietzsche se mostra tributário da filosofia de Schopenhauer. A julgar pela letra e pela intenção do primeiro capítulo da Terceira consideração extemporânea, Nietzsche também herda do homenageado uma concepção de filosofia que a vê como tentativa de resolução de um problema colocado imediatamente pela própria existência. Porém, a feição decididamente individual que este problema toma nas mãos do autor o diferencia de forma substancial daquele colocado por Schopenhauer na origem do filosofar. Para o autor de Schopenhauer como educador, o impulso à filosofia não vem de algum espanto filosófico diante da existência em geral, mas sim de uma tomada de consciência clara da própria existência individual como fenômeno único e absolutamente original. O gênio seria então justamente aquele em que esta tomada de consciência ocorre da forma mais clara possível, tendo como consequência a busca pela plena realização da individualidade. Estaria, então, o impulso ao filosofar profundamente ligado à percepção de que "todo homem é um milagre que só ocorre uma vez"25. A filosofia traria à consciência aquilo que na verdade todo o homem no fundo sabe ou intui: "que ele existe no mundo inusitadamente, como Unicum, e que nenhum acaso, por mais estranho que seja, combinará novamente uma tão multicor multiplicidade em uma unidade tal como ele é"26.

Assim sendo, a constatação que desencadeia o filosofar não seria tanto a da existência em geral, mas sim a da incontornável singularidade da existência individual. Enquanto tal, essa singularidade é algo totalmente distinto de qualquer essência geral da humanidade ou de qualquer imutável ideia do homem. E para compreendê-la é necessário levar em conta exatamente aquilo que Schopenhauer exclui da essência humana como superficial e circunstancial, ou seja, tudo o que deriva da influência da história e da cultura. Pois a verdade é que, para Nietzsche, não pode haver nenhuma

${ }^{25}$ Idem, parte 1, p. 337

${ }^{26}$ Ibidem, pp. 337-338.

Voluntas: Revista Internacional de Filosofia - periodicos.ufsm.br/voluntas - Santa Maria - Vol. 9, n. 1, jan.-jun. 2018, pp. 53-67 
essência humana independente da cultura e de sua história. Pelo contrário, a cultura é força internamente formadora, profundamente determinante do sujeito humano, e esta formação do homem pela cultura tem primeiramente um caráter tradicional e coletivo. Apesar de todas as transformações por que passa, o conceito nietzscheano de cultura implica sempre a ideia de certo patrimônio espiritual e intelectual com cuja absorção selamos nosso pacto de pertencimento a uma comunidade e nos conectamos a certas tradições coletivas, sendo esta absorção a condição básica e inescapável para a constituição de todo e qualquer ser humano, propriamente dito. A cultura nada mais é que a ambiência ou o elemento apenas em meio ao qual se torna possível uma existência genuinamente humana, e todo ser humano só é de fato humano por haver herdado ou recebido em si uma tradição cultural. Pode-se então dizer que esta recep̧̧ão corresponde a um degrau básico e necessário de toda formação, compreendida no sentido nietzscheano mais estrito de processo de constituição da individualidade. Precisamente por ser constituição da individualidade, a formação não pode estacionar nesse degrau inicial: como processo radicalmente individualizante, ela só pode dar-se como negação, ou pelo menos relativização dessa formação tradicional e coletiva. Certamente que esta última não é como uma veste da qual o sujeito se pudesse despir, a fim de encontrar qualquer individualidade "pura e imaculada": de certo condicionamento cultural, como já afirmamos, nem mesmo o gênio (que a terceira consideração extemporânea aponta como indivíduo maximamente consumado), consegue isentar-se totalmente. Mas se é verdade que todos nós carregamos necessariamente uma dimensão tradicional e coletiva, e, portanto, estritamente não individual de nosso ser, é também verdade que o apego atávico e instintivo a essa dimensão básica da formação acomete os homens em graus variados, e, de fato, em graus inversamente proporcionais aos das suas respectivas propensões filosóficas.

Significativamente, Schopenhauer como educador inicia-se com a constatação de que esse apego é endêmico no gênero humano: a imensa maioria dos homens não se mostra minimamente interessada em compreender e cultivar a singularidade de sua existência. Mas o texto não explica esse fato como decorrência de qualquer limitação intelectual, e sim de uma espécie de insuficiência ou vício moral: a preguiça ${ }^{27}$. A preguiça de que então se fala é antes de tudo a renúncia à individualidade, o deixar-se amparar comodamente nas formas tradicionais de pensar e agir, o passivo deixar-se determinar pelos condicionamentos que necessariamente nos vêm de pertencermos a uma cultura e existirmos em um dado momento histórico. Ora, a inclinação filosófica aponta na direção exatamente oposta, e por isso tem como condição subjetiva certa intrepidez e obstinação do espírito, na busca não exatamente de qualquer essencialidade perdida e esquecida, mas sim de um ativo assenhorear-se de si mesmo. Pois aquela individualidade cujo vislumbre é a fagulha inicial do filosofar existe, na

\footnotetext{
${ }^{27}$ Ibidem.
} 
verdade, muito mais como tarefa do que como fato: "tua essência verdadeira", diz Nietzsche, "não está oculta no fundo de ti, mas colocada infinitamente acima de ti" 28. Ela é nomeadamente algo a ser construído a partir da base tradicional e coletiva de nosso ser, exatamente na medida em que se aprende a reconhecê-la como fator condicionante e limitador do desenvolvimento de uma verdadeira individualidade. Assim é que nesse conbece a ti mesmo que Nietzsche coloca no início da filosofia está implícito, como seu sentido mais profundo, um faz a ti mesmo, ou "sê tu mesmo", pois equivale à percepção de que "do que tu agora fazes, pensas e desejas, nada disso és tu"29. A filosofia, portanto, tem a ver fundamentalmente com a busca de um pleno dispor de si mesmo: “Temos de assumir perante nós mesmos a responsabilidade por nossa existência, assim sendo, queremos agir como os verdadeiros timoneiros desta vida, e não permitir que nossa existência pareça um acaso irrefletido" 30 . Por isso, formação, no sentido de formação individual, é para Nietzsche, essencialmente libertação. Ela é "remoção de todas as ervas daninhas, dos entulhos, dos vermes que querem atacar as delicadas sementes das plantas ${ }^{31 "}$ ". A ação do educador, portanto, consiste em tornar possível o desenvolvimento autônomo de uma individualidade, afastando de seu caminho tudo aquilo que o possa impedir. Mas a tarefa principal e decisiva não está sob responsabilidade do educador, e sim do educando, pois sua autonomia tem de ser sua própria obra: "ninguém pode construir para ti a ponte através da qual precisas ultrapassar o rio da vida, ninguém além de ti [...]"32.

Vale a pena comparar estas passagens com certas imagens utilizadas por Nietzsche em Humano, demasiado humano I, em que ele descreve os ardis utilizados pela natureza para a criação do gênio:

[...] ela o prende num cárcere e estimula ao máximo seu desejo de se libertar. - Ou, para recorrer a outra imagem: alguém que se perdeu completamente ao caminhar pela floresta, mas com energia invulgar se esforça para achar uma saída, descobre às vezes um caminho que ninguém conhece: assim se formam os gênios, dos quais se louva a originalidade ${ }^{33}$.

Tais metáforas também servem para descrever a geração do espirito livre, pois a pergunta por sua produção não é outra coisa que, "num caso particular, o problema da produção do gênio". "De onde vem", pergunta-se Nietzsche, "a energia, a força inflexível, a perseverança com que alguém, opondo-se à tradição, procura um conhecimento inteiramente individual do mundo?"34 Qualquer que seja sua natureza,

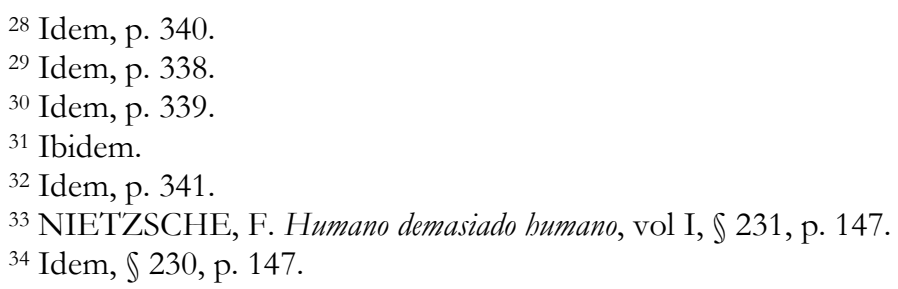


essa energia, essa força inflexivel é aquela que distingue os verdadeiros filósofos. O espírito livre, personagem que representa a mais elevada possibilidade de existência trazida pela cultura moderna, nada mais é que o gênio filosófico. Assim o define Nietzsche:

É chamado de espírito livre aquele que pensa de modo diverso do que se esperaria com base sua procedência, seu meio, sua posição e função, ou com base nas opiniões que predominam em seu tempo. Ele é a exceção, os espíritos cativos são a regra ${ }^{35}$.

Sendo o espírito cativo exatamente aquele que pensa de acordo com o que se esperaria dele com base em todos esses fatores mencionados na citação, facilmente se percebe que entre ele e o espirito livre se reproduz a mesma a relação que se verifica entre o indolente comum dos homens, segundo a expressão que usamos acima, e o homem de Schopenhauer. Esta última relação, por sua vez, se decalca da oposição que o próprio Schopenhauer, em seu texto sobre a filosofia universitária, estabelece entre o comum e corrente produto de fábrica da natureza e o verdadeiro filósofo. Aquele permanece preso no cárcere ou na selva fechada das tradições venerandas, das opiniões canônicas, das formas sancionadas do pensar e sentir. É justamente desse cárcere e dessa selva que o espírito livre, por meio da filosofia, se libertou. Pois, como observa Nietzsche no texto de Ecce Homo sobre Humano, demasiado humano, "em nenhum outro sentido deseja a expressão espírito livre ser aqui compreendida: um espírito que se libertou (ein freigewordner Geist), que se apossou novamente de si mesmo"36. Com esse livro para espiritos livres, proclama o autor sua própria liberdade: "com ele libertei-me de coisas que não pertenciam à minha natureza" 37 . Entre essas coisas que não pertenciam à minha natureza, como se depreende claramente da obra em questão, estão certamente Schopenhauer e o pensamento metafísico em geral. É, contudo, interessante notar que, exatamente no momento em que Nietzsche proclama publicamente sua independência ao schopenhauerianismo, reforçam-se os traços profundos de uma concepção de filosofia que ele aprendeu com Schopenhauer. Mas também ao seguir seu próprio caminho ele se mostra schopenhaueriano, pois para aquele "verdadeiro filósofo", como já vimos, "o verdadeiro filosofar exige independência”.

\section{Referências bibliográficas}

NIETZSCHE, F. Sämtliche Werke. Kritische Studienausgabe, edição de Colli e Montinari. Berlin: de Gruyter, 1980.

NIETZSCHE, F. Humano, demasiado Humano I. São Paulo: Companhia das Letras, 2013.

\footnotetext{
35 Idem, \225, p. 143.

36 NIETZSCHE, F. Ecce Homo, KSA, vol. 6, p. 322.

${ }^{37}$ Ibidem.
} 
SCHOPENHAUER, A. Schopenhauers Sämtliche Werke. Hrsg. von Paul Deussen. München: Piper Verlag, 1911-1926. In: CD-ROM Schopenhauer im Kontext, Werkausgabe I, Berlin, Karsten Worm, 2001.

SCHOPENHAUER, A. O mundo como vontade e como representação. Tomo I. São Paulo: Editora Unesp, 2005.

Recebido: 30/04/18 Received: $04 / 30 / 18$

Aprovado: $27 / 05 / 18$ Approved: 05/27/18 